\title{
Inhibition of glycolysis and growth of colon cancer cells by 3-(3- pyridinyl)-1-(4-pyridinyl)-2-propen-1-one (3PO) in combination with butyrate, 2-deoxy glucose, 3-bromopyruvate or biguanides
}

\author{
Michael A. Lea ${ }^{1 *}$, Raymond Geherty ${ }^{1}$ and Charles desBordes ${ }^{1,2}$ \\ 1 Department of Microbiology, Biochemistry and Molecular Genetics, Rutgers New Jersey Medical School, Newark, New Jersey, USA \\ 2 Department of Biology, Medgar Evers College - City University of New York, Brooklyn, NY, USA
}

\begin{abstract}
Introduction: Glycolysis shows a positive correlation with growth of human colon cancer cells. PFKFB3 is an important enzyme regulating glycolysis in many tumor cells and presents a target for cancer chemotherapy. We studied the action of an inhibitor of PFKFB3, 3-(3pyridinyl)-1-(4-pyridinyl)-2-propen-1-one (3PO), as a single agent and in combination with other molecules that affect glycolysis. Materials and methods: Effects on growth were studied in four human colon cancer cell lines. Glucose metabolism was monitored by uptake from the incubation medium and lactic acid production was judged by acidification of the medium. Induction of alkaline phosphatase served as a marker of differentiation. Results: Growth of colon cancer cells was inhibited by 3PO and butyrate but only butyrate induced activation of alkaline phosphatase. Although metformin and phenformin can increase glucose metabolism, they inhibit colon cancer cell growth and can exert additive inhibitory effects in combination with 3PO. Additive growth inhibitory effects with 3PO were also observed with two compounds that inhibit glycolysis: 2-deoxyglucose and 3-bromopyruvate. Conclusion: 3PO was an inhibitor of growth of colon cancer cells and may be a useful agent in combination with other drugs that inhibit colon cancer cell proliferation.
\end{abstract}

Keywords: Colon cancer cells; glycolysis; growth; PFKFB3 inhibitor; butyrate; phenformin; metformin; 2-deoxyglucose; 3-bromopyruvate

\section{Introduction}

In human colon cancer cells, glycolytic activity shows a positive correlation with proliferation. Regulation of glycolysis is exerted particularly at the level of phosphofructokinase 1. Thatenzyme is activated by fructose 2,6-bisphosphate the levels of which are controlled by the bifunctional enzymes with phosphofructosekinase 2 and fructose 2,6-biphosphatase activities (PFKFBs). PFKFB3 is an important enzyme regulating glycolysis in many tumor cells. We have studied the action of 3-(3-pyridinyl)-1-(4pyridinyl)-2-propen-1-one (3PO), an inhibitor of PFKFB3, as a single agent and in combination with other molecules that affect glycolysis and proliferation in four colon cancer cell lines (Caco-2, HCT116, HT29 and SW1116). The molecules studied were 3-bromopyruvate, butyrate, 2-deoxyglucose, and the biguanides metformin and phenformin that have been found previously to inhibit the proliferation of colon cancer cells [1-3].

\section{Materials and methods}

Reagents: 3-(3-pyridinyl)-1-(4-pyridinyl)-2-propen-1-one was purchased from EMD Millipore, Billerica, MA, USA. Sodium butyrate, 2-deoxyglucose, 3-bromopyruvate, metformin and phenformin were obtained from Sigma-Aldrich, St. Louis, MO, USA.

Cells and determination of cell proliferation: SW1116, HCT116, HT29, and Caco-2 human colon cancer cells were obtained from American Type Culture Collection, Rockville, MD, USA, and were incubated at $37^{\circ} \mathrm{C}$ in RPMI1640 medium with $5 \%$ fetal calf serum. Of these cell lines, the HCT116 cells exhibited the most rapid proliferation and the slowest growth was seen with the SW1116 cells. Cell proliferation was generally monitored by the increase in protein determined by staining with sulforhodamine B essentially as described by Vichai and Kirtikara [4].

Enzyme assays: Alkaline phosphatase was assayed using para-nitrophenyl phosphate as a substrate. Formation of product was monitored by the change in absorbance at $410 \mathrm{~nm}$.

*Corresponding author: Michael A. Lea, Ph.D., Department of Microbiology, Biochemistry and Molecular Genetics, Rutgers New Jersey Medical School, 225 Warren Street, Newark, New Jersey, 07103, USA. Tel.: +1-973-972-5345: Fax: +1-973-972-1286; Email: lea@njms.rutgers.edu

Received 21 June 2015 Revised 18 August 2015 Accepted 24 August 2015 Published 31 August 2015

Citation: Lea MA, Geherty R, desBordes C. Inhibition of glycolysis and growth of colon cancer cells by 3-(3-pyridinyl)-1-(4-pyridinyl)-2-propen-1one (3PO) in combination with butyrate, 2-deoxy glucose, 3-bromopyruvate or biguanides. J Cancer Res Ther. 2015; 3(8):92-99. DOI:10.14312/20524994.2015-13

Copyright: () 2015 Lea MA, et al. Published by NobleResearch Publishers. This is an open-access article distributed under the terms of the Creative Commons Attribution License, which permits unrestricted use, distribution and reproduction in any medium, provided the original author and source are credited. 
$\mathrm{pH}$ determination: $\mathrm{pH}$ determination with an electrode was found previously to correlate well with changes in the light absorbance at $560 \mathrm{~nm}$ reflecting changes in the $\mathrm{pH}$ indicator, phenol red [1].

Glucose assay: Glucose was assayed in the cell culture medium using Kit GAGO-20 from Sigma-Aldrich, St. Louis, MO, USA. This is a colorimetric procedure in which the oxidation of glucose is coupled with glucose oxidase and peroxidase to the oxidation of dianisidine.

\section{Statistical evaluation}

Data are presented as means and standard deviations for six or a greater number of determinations. Statistical significance of the results was determined by a twotailed Student's t-test or by Dunnett's test for multiple comparisons. A probability of less than $5 \%$ was considered significant.

\section{Results}

Incubation of many colon cancer cell lines with $1 \mathrm{mM}$ butyrate is known to inhibit growth and induce the activity of alkaline phosphatase. This is illustrated for Caco-2 (Figure 1A and 1D), HT29 (Figure 1B and 1E) and SW1116 cells (Figure $1 \mathrm{C}$ and $1 \mathrm{~F}$ ). The activity of alkaline phosphatase is often used as a marker of differentiation in colon cancer cells. Growth inhibitory effects were also seen when these cell lines were incubated with 3PO (Figure $1 \mathrm{~A}, 1 \mathrm{~B}$ and $1 \mathrm{C})$, but this action was not accompanied by an increase in alkaline phosphatase activity (Figure 1D, 1E and $1 \mathrm{~F}$ ). Additive effects on growth were seen when Caco-2 cells were incubated with a combination of $5 \mu \mathrm{M} 3 \mathrm{PO}$ and 1 mM butyrate (Figure 1A) and when HT29 and SW1116 cells were incubated with a combination of $10 \mu \mathrm{M} 3 \mathrm{PO}$ and 1 $\mathrm{mM}$ butyrate (Figure1B and 1C).

The rapidly growing HCT116 colon cancer cells do not have significant alkaline phosphatase activity and activity was not induced by incubation with $1 \mathrm{mM}$ butyrate (data not shown). However, growth inhibition was observed when HCT116 cells were incubated with $1 \mathrm{mM}$ butyrate or 10 $\mu \mathrm{M} 3 \mathrm{PO}$ (Figure 2A). These actions were accompanied by decreased acidification of the medium (Figure 2B) and decreased glucose uptake (Figure 2C). Additive effects of combined incubation with $10 \mu \mathrm{M} 3 \mathrm{PO}$ and $1 \mathrm{mM}$ butyrate were seen on growth, medium acidification and glucose uptake.

Inhibitory effects on growth were observed with 3PO and the biguanides, phenformin and metformin (Figure 3A-D). Additive effects with combined treatment with $3 \mathrm{PO}$ and a biguanide were more apparent with Caco-2, HCT116 and HT29 cells than with the more slowly growing SW1116 cells. Effects of 3PO and biguanides on medium acidification and glucose uptake are more readily observed in the more rapidly growing HCT116 and HT29 cells than the more slowly growing Caco-2 and SW1116 cells. Results for HCT116 and HT29 cells are shown in Figure 4A-D. The data for HT29 cells show the phenomenon seen with some cancer cell lines in which biguanides cause increased medium acidification and increased glucose uptake under conditions in which there is an inhibition of growth. The action of biguanides on glycolysis and glucose uptake was partially reversed by combined incubation with $10 \mu \mathrm{M}$ 3PO, which as a single agent tends to decrease medium acidification and glucose uptake.

The effect of combined treatment with 3PO and 2-deoxyglucose on growth and medium acidification is shown for Caco-2, HCT116 and HT29 cells in Figure 5A-F. Both compounds can exert inhibitory effects on glycolysis and additive inhibitory effects could be observed on growth and on medium acidification. That was also the case when a further combination of inhibitors of glycolysis, namely 3PO and 3-bromopyruvate was examined. The results for studies with Caco-2 and HCT116 cells are shown in Figure 6A-D.

\section{Discussion}

The tendency of cancer cells to have enhanced rates of glycolysis has been recognized since the early work of Warburg [5, 6]. Although this presents a potential target for chemotherapeutic intervention, the lack of specific inhibitors has been a long-standing problem. The recognition that fructose 2,6-bisphosphate is an important regulatory molecule for the activation of glycolysis directed attention to the bifunctional enzymes that control the level of that compound, the PFKFBs. A number of investigators have sought small inhibitory compounds for PFKFB3 [7-10] on the basis that PKKFB3 activity is elevated in many types of cancer and has high phosphofructo-2-kinase activity $[7,11,12]$. Cancer chemotherapy is characterized by combination therapies that deter the development of resistance and may permit lower doses of individual compounds. Additive effects have been seen with 3PO and an inhibitor of autophagy against HCT116 human colon cancer cell lines [13]. In the present work, combinations have been studied of 3PO and some compounds that also inhibit glycolysis: butyrate, 2-deoxyglucose and 3-bromopyruvate. Butyrate is a nutrient for normal colonocytes. In addition, it is a broad-spectrum inhibitor of histone deacetylases and a differentiating agent for some cancer cell lines. 2-deoxyglucose is known to inhibit glycolysis after conversion to 2-deoxyglucose 6-phosphate but it can also affect mannose metabolism. It might be noted that 2-deoxyglucose is identical to 2-deoxymannose. 3-bromopyruvate has been widely studied since its identification as an inhibitor of tumor growth [14]. The action of 3-bromopyruvate has been attributed particularly to inhibition of hexokinase and glyceraldehyde-3-phosphate dehydrogenase but the compound may react with other cellular components. The low extracellular $\mathrm{pH}$ of tumors will favor the cytotoxicity of 3-bromopyruvate [15].

In colon cancer cells the induction of alkaline phosphatase activity by butyrate has been used as a marker of differentiation. Increased alkaline phosphatase activity in response to butyrate treatment was seen in three of the colon cancer cells examined, Caco-2, HT29 and SW1116. It was not observed with HCT116 cells but those cells, like the others, were subject to growth inhibition when treated with butyrate. It is clear that the differentiating effect of butyrate does not have a simple relationship to growth inhibition. This observation was reinforced by the finding 

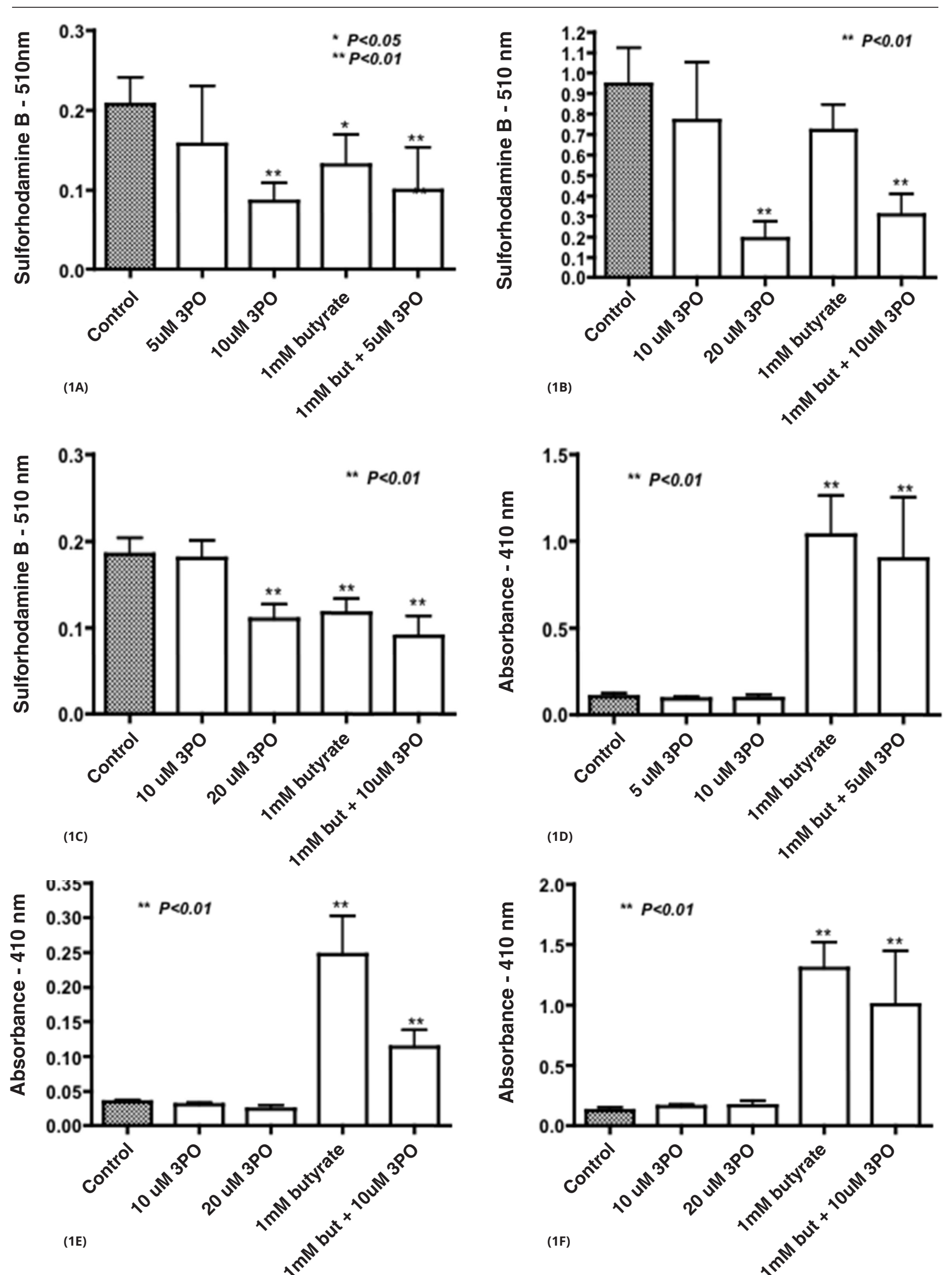

Figure 1 Effects of $3 \mathrm{PO}$ and butyrate on growth (A-C) and alkaline phosphatase activity (D-F) of Caco-2 (A,D), HT29 (B,E) and SW1116 (C,F) colon cancer cells after a $72 \mathrm{~h}$ incubation. 


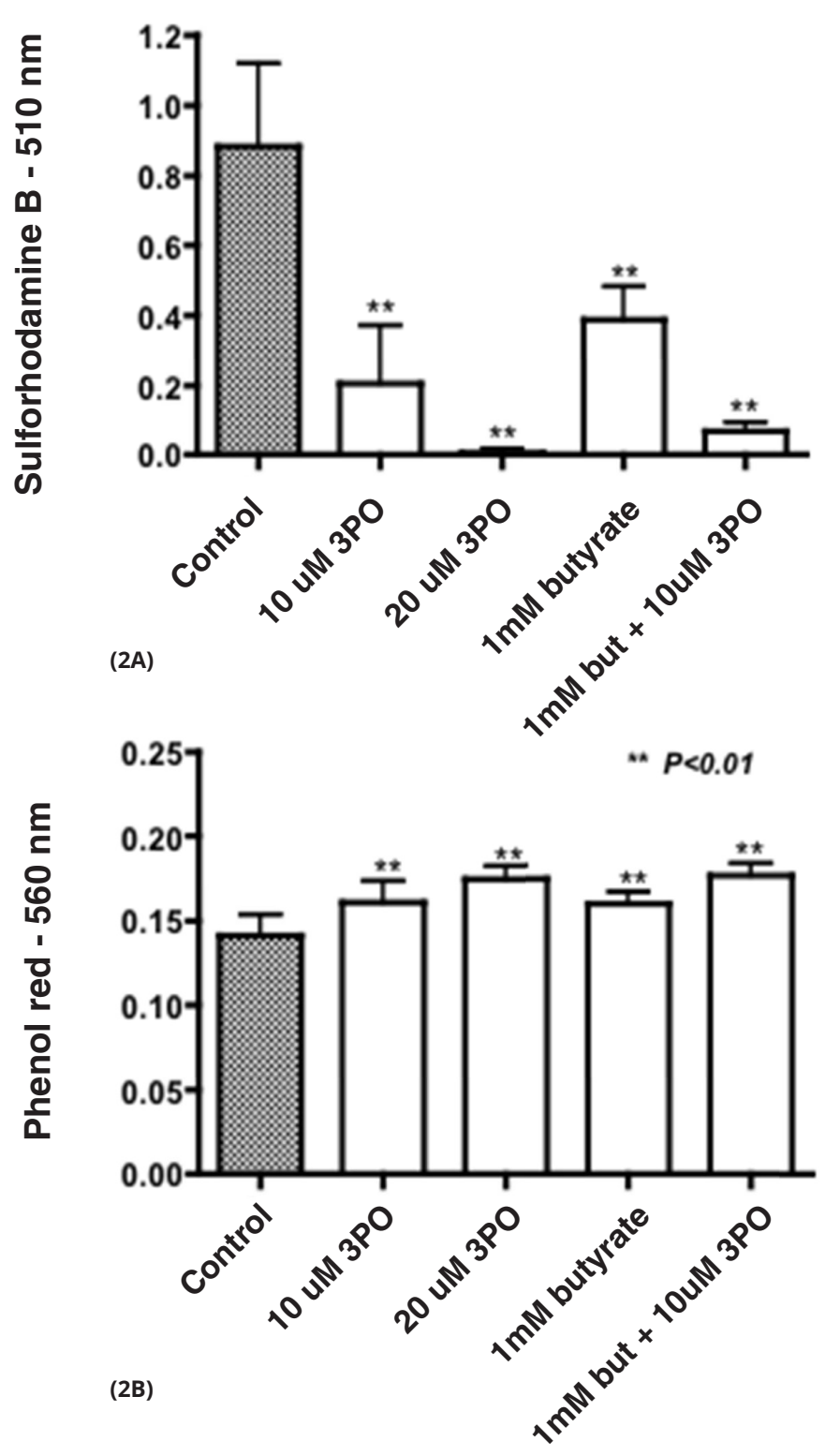

that there was no induction of alkaline phosphatase activity when growth was inhibited by incubation with $3 \mathrm{PO}$.

The biguanides, metformin and phenformin, are unusual in as much as they can enhance glucose uptake and metabolism under conditions in which cell proliferation is inhibited. In previous work the enhanced glucose metabolism caused by the biguanides was found to be blocked by butyrate, 2-deoxyglucose and 3-bromopyruvate [2]. In the present work the effects of biguanides on glucose metabolism were reversed by coincubation with $3 \mathrm{PO}$. Despite having opposing effects on glucose metabolism, 3PO and the biguanides could exert additive inhibitory effects on the growth of colon cancer cells.

3PO was the first commercially available PFKFB3 inhibitor. Related structures have been synthesized that are effective at lower concentrations [16] and work is ongoing to optimize pharmacokinetic and tumor-selective action. Attention is also being given to inhibitors of PFKFB4 [17]. The present work relates to combinations with effects on glucose metabolism and combination studies with chemotherapeutic agents with other modes of action may
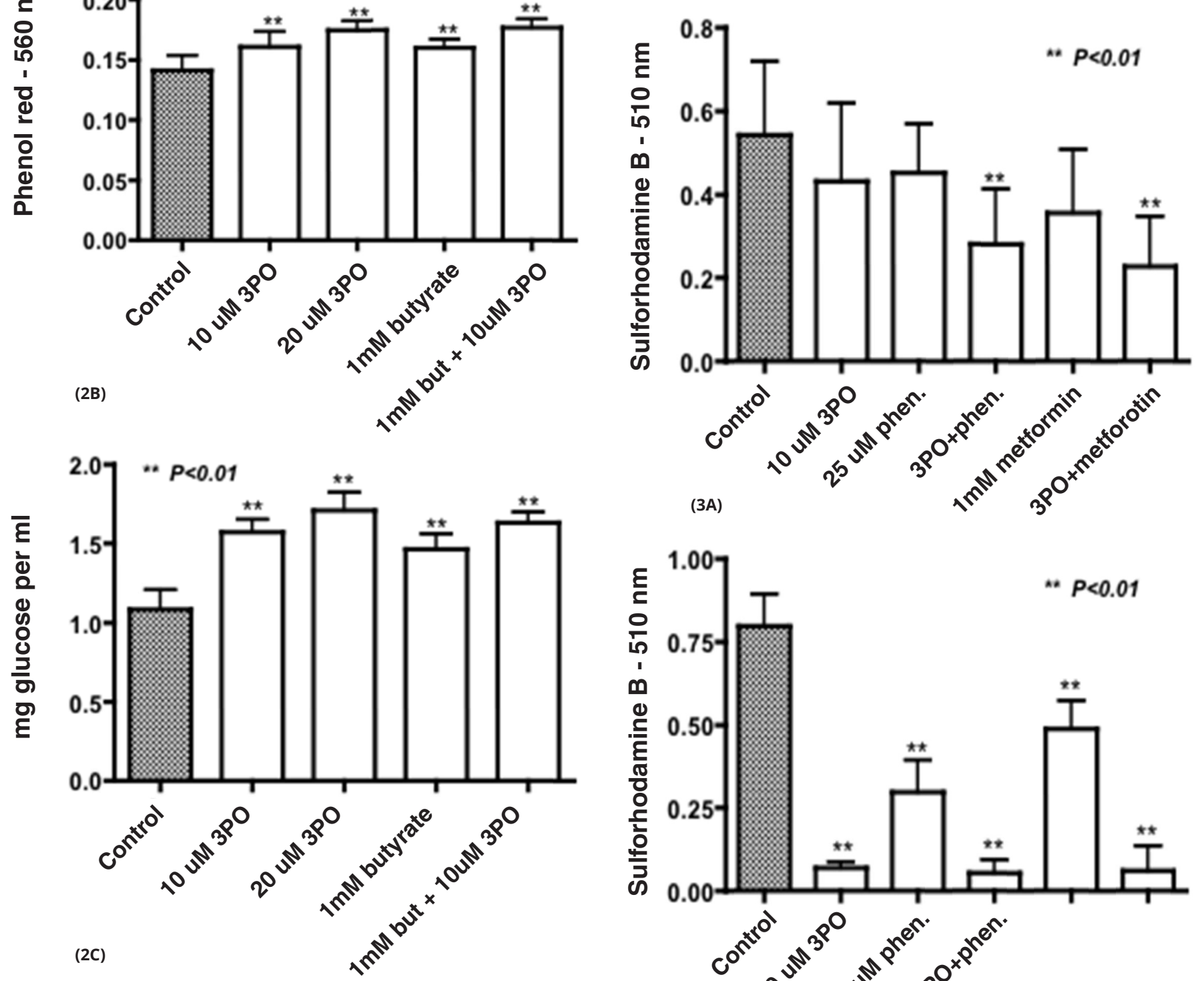

Figure 2 Effects of $3 \mathrm{PO}$ and butyrate on growth (A), medium $\mathrm{pH}(\mathrm{B})$ and glucose concentration (C) of HCT116 cells after a $72 \mathrm{~h}$ incubation. The initial glucose concentration was $2 \mathrm{mg}$ per $\mathrm{ml}$.

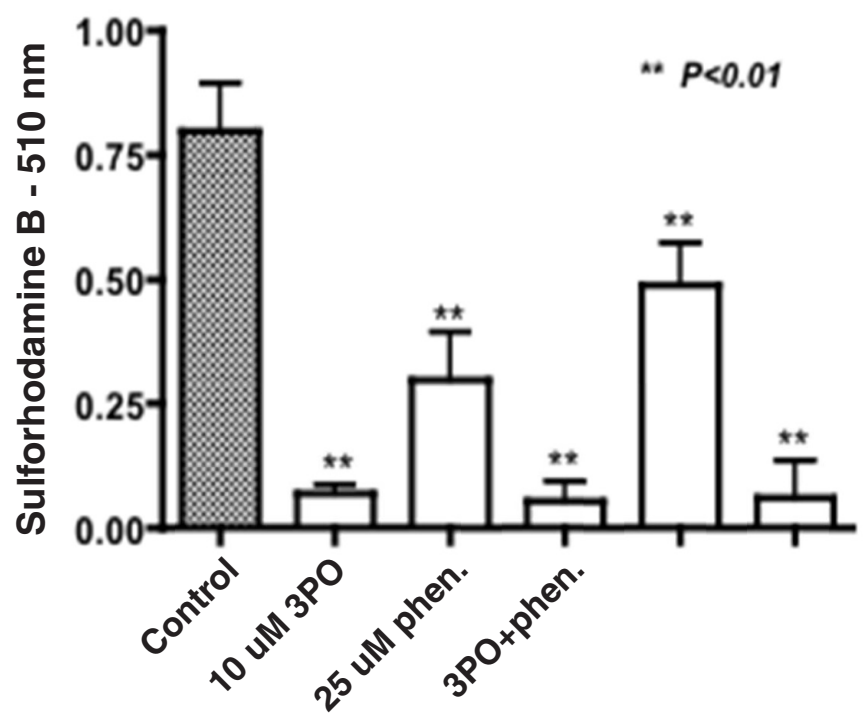

(3B) 

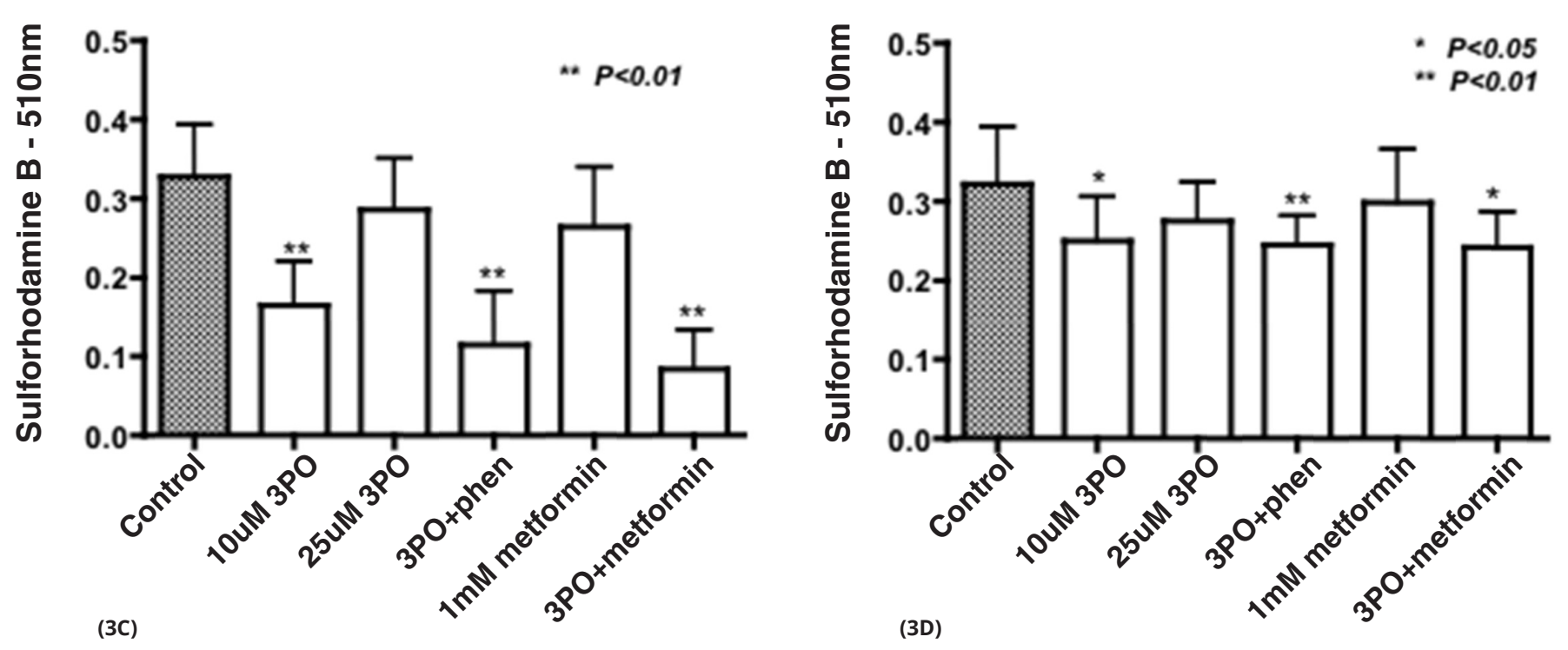

Figure 3 Effects of $10 \mu \mathrm{M}$ 3PO, $25 \mu \mathrm{M}$ phenformin and $1 \mathrm{mM}$ metformin on growth of Caco-2 (A), HCT116 (B), HT29 (C) and SW1116 (D) colon cancer cells after a $72 \mathrm{~h}$ incubation.
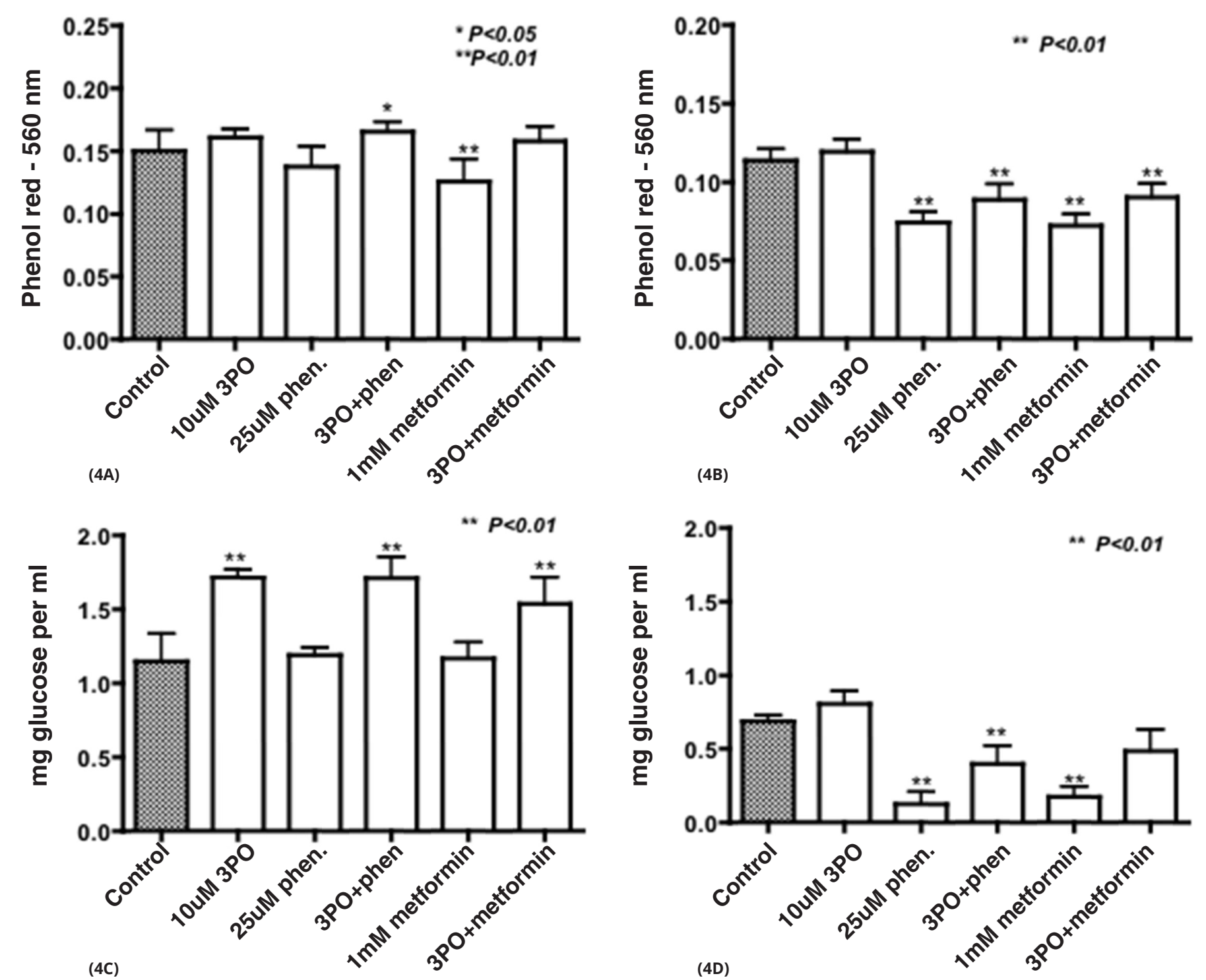

Figure 4 Effects of 3PO, phenformin and metformin on medium $\mathrm{pH}(\mathrm{A}, \mathrm{B})$ and glucose concentration (C, D) after a $72 \mathrm{~h}$ incubation of HCT116 (A, C) and HT29 $(B, D)$ colon cancer cells. The initial glucose concentration was $2 \mathrm{mg}$ per $\mathrm{ml}$. 

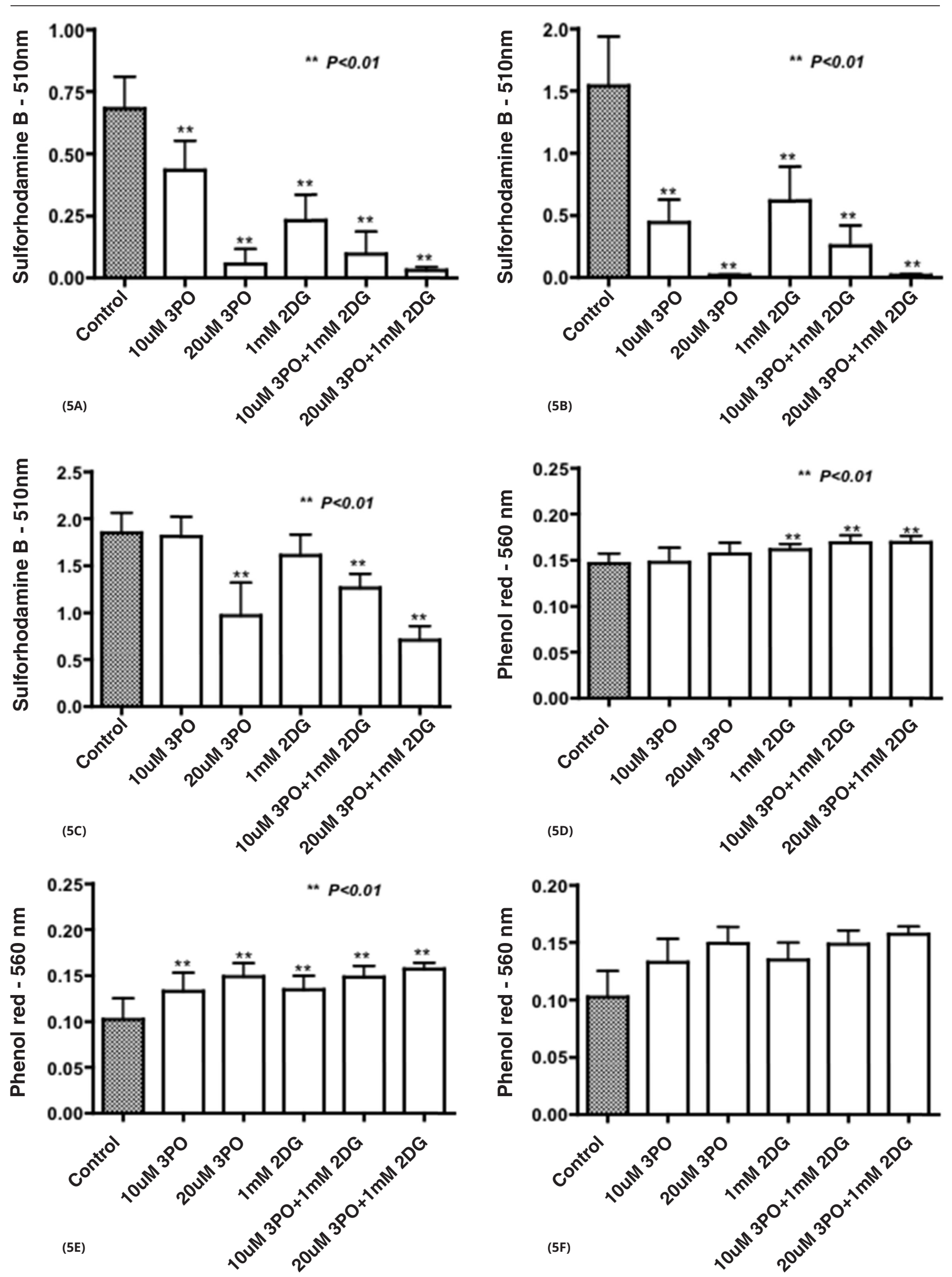

Figure 5 Effects of $3 \mathrm{PO}$ and 2-deoxyglucose on growth (A-C) and pH in the medium (D-F) of Caco-2 (A, D), HCT116 (B,E) and HT29 (C, F) of colon cancer cells after a $72 \mathrm{~h}$ incubation. 

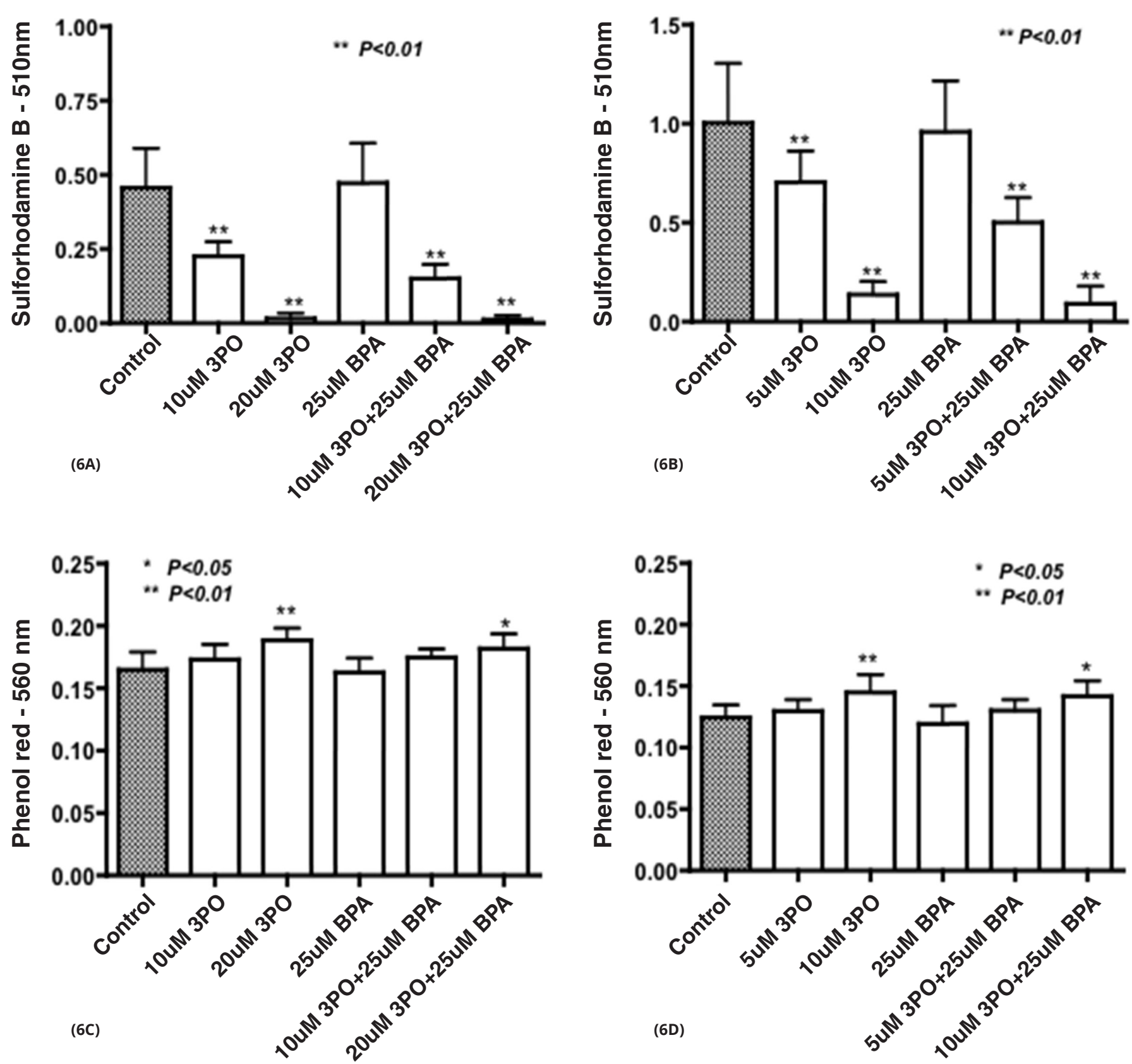

Figure 6 Effects of 3PO and 3-bromopyruvate on growth (A, B) and pH in the medium (C, D) of Caco-2 (A, C) and HCT116 (B, D) colon cancer cells after a $72 \mathrm{~h}$ incubation.

be anticipated. There is considerable current interest in targeting cancer metabolism as a therapeutic approach $[18,19]$. For those tumors that are addicted to glucose metabolism, PFKFB3 inhibitors appear promising agents for combination therapy.

\section{Conclusion}

3PO was an inhibitor of proliferation of colon cancer cells, especially the rapidly growing HCT116 and HT29 cell lines. 3PO and related molecules may be useful agents in combination with other drugs that inhibit colon cancer cell proliferation.

\section{Acknowledgment}

This research was supported by the Alma Toorock Memorial for Cancer Research.

\section{Conflict of interest}

The authors declare no conflict of interest

\section{References}

[1] Lea MA, Chacko J, Bolikal S, Hong JY, Chung R, et al. Addition of 2-deoxyglucose enhances growth inhibition but reverses acidification in colon cancer cells treated with phenformin. Anticancer Res. 2011; 31(2):421-426.

[2] Lea MA, Qureshi MS, Buxhoeveden M, Gengel N, Kleinschmit J, et al. Regulation of the proliferation of colon cancer cells by compounds that affect glycolysis, including 3-bromopyruvate, 2-deoxyglucose and biguanides. Anticancer Res. 2011; 33(2):401-407.

[3] Lea MA, Pourat J, Patel R, desBordes C. Growth inhibition of colon cancer cells by compounds affecting AMPK activity. World J Gastrointest Oncol. 2014; 6(7):244-252.

[4] Vichai V, Kirtikara K. Sulforhodamine B colorimetric assay for cytotoxicity screening. Nat Protoc. 2006; 1(3):1112-1116. 
[5] Warburg O, Posener K, Negelein E. Ueber den Stoffwechsel der Tumoren. Biochem Z. 1924; 152:319-344.

[6] Warburg O. On the origin of cancer cells. Science. 1956; 123(3191):309314.

[7] Clem B, Telang S, Clem A, Yalcin A, Meier J, et al. Small-molecule inhibition of 6-phosphofructo-2-kinase activity suppresses glycolytic flux and tumor growth. Mol Cancer Ther. 2008; 7(1):110-120.

[8] Seo M, Kim JD, Neau D, Sehgal I, Lee YH. Structure-based development of small molecule PFKB3 inhibitors: a framework for potential cancer therapeutic agents targeting the Warburg effect. PLoS One. 2011; 6(9):e24179.

[9] Brooke DG, van Dam EM, Watts CKW, Khoury A, Dziadek, MA, et al. Targeting the Warburg effect in cancer; relationships for 2-arylpyridazinones as inhibitors of the key glycolytic enzyme 6-phosphofructo-2-kinase/2,6-bisphosphatase 3 (PFKFB3). Bioorg Med Chem. 2014; 22(3):1029-1039.

[10] Boyd S, Brookfield JL, Critchlow SE, Cummings IA, Curtis NJ, et al. Structure-based design of potent and selective inhibitors of the metabolic kinase PFKFB3. J Med Chem. 2015; 58(8):3611-3625.

[11] Atsumi T, Chesney J, Metz C, Leng L, Donnelly S, et al. High expression of inducible 6-phosphofructo-2-kinase/fructose-2,6-bisphosphatase (iPFK-2; PFKFB3) in human cancers. Cancer Res. 2002; 62(20):58815887.

[12] Yalcin A, Telang S, Clem B, Chesney J. Regulation of glucose metabolism by 6-phosphofructo-2-kinase/fructose-2,6-bisphosphatases in cancer. Exp Mol Pathol. 2009; 86(3):174-179.

[13] Klarer AC, O'Neil J, Imbert-Fernandez Y, Clem A, Ellis SR, et al. Inhibition of 6-phosphofructo-2-kinase (PFKFB-3) induces autophagy as a survival mechanism. Cancer Metabolism. 2014; 2(1):2.

[14] Ko YH, Smith BL, Wang Y, Pomper MG, Rini DA, et al. Advanced cancers: eradication in all cases using 3-bromopyruvate therapy to deplete ATP. Biochem Biophys Res Commun. 2004; 324(1):269-275.

[15] Azevedo-Silva J, Queiros O, Ribeiro A, Baltazar F, Young KH, et al. The cytotoxicity of 3-bromopyruvate in breast cancer cells depends on extracellular pH. Biochem J. 2015; 467(2):247-258.

[16] Clem BF, O'Neal J, Tapolsky G, Clem AL, Imbert-Fernandez $Y$, et al. Targeting of 6-phosphofructo-2-kinase (PFKFB3) as a therapeutic strategy against cancer. Mol Cancer Ther. 2013; 12(8):1461-1470.

[17] Chesney J, Clark J, Klarer AC, Imbert-Fernandez Y, Lane AN et al. Fructose-2,6-bisphosphate synthesis by 6-phosphofructo-2-kinase/ fructose-2,6-bisphosphatase 4 (PFKFB 4) is required for the glycolytic response to hypoxia and tumor growth. Oncotarget. 2014; 5(16):66706686.

[18] Kinnaird A, Michelakis ED. Metabolic modulation of cancer: a new frontier with great translational potential. J Mol Med. 2015; 93(2):127142.

[19] Kim SY. Cancer metabolism: strategic diversion from targeting cancer drivers to targeting cancer suppliers. Biomol Ther. 2015; 23(2):99109. 